\title{
Investigation of the Performance Characteristics of the Angle-based Proportional Navigation Guidance Law
}

\author{
Bülent Özkan ${ }^{1 *}$ \\ $\mathbf{1}^{*}$ Gazi University, Faculty of Engineering, Mechanical Engineering Department, Ankara, Turkey, (ORCID: 0000-0003-3112-9723), bozkan@,gazi.edu.tr
}

(1st International Conference on Applied Engineering and Natural Sciences ICAENS 2021, November 1-3, 2021)

(DOI: 10.31590/ejosat.1006720)

ATIF/REFERENCE: Özkan, B. (2021). Investigation of the Performance Characteristics of the Angle-based Proportional Navigation Guidance Law. European Journal of Science and Technology, (28), 1172-1178.

\begin{abstract}
Guidance commands generated by the proportional navigation guidance (PNG) law which constitutes the most popular one among the guidance laws applied on the guidance munition fired against predetermined targets are in the form of linear acceleration or angular speed as dictated by the relevant engagement geometry. As a result of the studies in which notable linear acceleration- and angle-based guidance laws are compared, it is seen the lateral acceleration values obtained with the PNG law occur in a lower level than the results of the angle-based guidance laws. However, the angle-based guidance laws lead to lower final miss distances. In this study, the PNG law is so adapted that it yields angle-based guidance commands and then it is applied upon a short range air-to-surface missile against a maneuvering surface target as well as the velocity pursuit guidance law that is nothing but a version of PNG law, linear homing guidance law, and body pursuit guidance law. After the computer simulations, it is observed that the angle-based PNG law produces smaller final miss distances compared to its original form. The resulting lateral accelerations are in admissible levels. Also, the engagement duration values with the target happen to be almost the same.
\end{abstract}

Keywords: Guidance, Proportional Navigation Guidance, Guided Munition, Acceleration-based Guidance, Angle-based Guidance.

\section{Açı Komutu Esaslı Oransal Seyrüsefer Güdüm Kuralının Başarım Özelliklerinin İncelenmesi}

Öz

Güdümlü mühimmatı önceden belirlenen hedeflere yönlendirmek amacıyla uygulanan güdüm kurallarından en popüleri olan oransal seyrüsefer (OS) güdüm kuralı tarafından üretilen güdüm komutları, ilgili eşleşme geometrisinin öngördüğü üzere doğrusal ivme veya açısal hız formundadır. Doğrusal ivme ve açı esaslı başlıca güdüm kurallarının karşılaştırıldığı çalışmalarda OS ile elde edilen azami yanal ivme değerlerinin açı esaslı güdüm kurallarının sonuçlarından daha düşük olduğu, buna karşın hedeften nihai sapma bakımından açı esaslı yöntemlerin üstün olduğu görülmüştür. Bu çalışmada, OS güdüm kuralı açı esaslı güdüm komutları üretecek şekilde uyarlanmış ve OS'nin bir türevi olan hız takibi güdüm kuralı ile doğrusal hedef takibi ve gövde takibi kurallarıyla birlikte manevra yapan bir yer hedefine karşı havadan firlatılan kısa menzilli bir füzeye uygulanmıştır. Bilgisayar benzetimleri sonucunda açı esaslı OS kuralının orijinal formuna göre daha düşük hedeften nihai sapma ürettiği ve kabul edilebilir düzeyde yanal ivmeye sebebiyet verdiği gözlenmiştir. Hedefle eşleşme süresi için elde edilen sonuçlar ise birbirine yakın çıkmıştır.

Anahtar Kelimeler: Güdüm, Oransal Seyrüsefer Güdüm, Güdümlü Mühimmat, İvme Esaslı Güdüm, Açı Esaslı Güdüm.

\footnotetext{
*Corresponding Author: bozkan@gazi.edu.tr
} 


\section{Introduction}

It is vital to make the motion planning of autonomous munition including missiles and smart bombs in a convenient manner in order to orient them towards specified targets with high precision. Regarding the autonomous munition, the conventional approach in the motion planning is the guidance and control algorithms. The guidance schemes constructed in the form of kinematic relationships based on the engagement geometry between the munition under consideration and target often provides the munition with tracking and destroying the target successfully [1], [2].

Looking at the relevant literature, it is seen that the proportional navigation guidance (PNG) law constitutes the most popular guidance law because of its simplicity and effectiveness. Principally, the PNG attempts to nullify the time change of the angular displacements of the line of sight between the munition and target with respect to the horizontal and vertical planes of the Earth-fixed reference frame $\left(F_{0}\right)$. As per the mentioned strategy, the guidance commands of the PNG law are generated in the form of the lateral components of the linear acceleration vector or in the form of the time change of the flight path angles of the munition [1], [2].

Unlike the PNG law, some of the guidance laws including the linear homing guidance (LHG) and body pursuit guidance (BPG) laws yield guidance commands in the form of angles. As these angles are the flight path angles of the munition in the LHG law, the orientation angles of the munition with respect to the horizontal and vertical planes become the commands of the BPG law. Comparing the linear acceleration- and anglebased guidance laws, it is observed that the PNG law produces higher results than its angle-based counterparts in terms of the final miss distance criterion even though it seems to be more advantageous in the maximum lateral acceleration requirement. On the other hand, lower lateral acceleration values could be achieved with the angle-based guidance laws by utilizing an autopilot scheme having bandwidth profile which linearly increases in time. The cost of this improvement becomes a reasonable increment in the final miss distance value [3], [4], [5].

Angle-based guidance laws are utilized to the motion planning of the mechatronic systems other than autonomous guided munition. In this extent, it is shown by means of the computer simulations that the motion strategy to carry the considered autonomous robot manipulator, quadrotor, and tracked vehicle to predefined target points can be planned using a convenient guidance law depending on the designed scenario [3], [6], [7], [8].

In this study, the PNG law is tried to be expressed such that it generates the guidance commands in angular form for the sake of improving its resultant final miss distance value and implementing it to mechatronic systems other than guided munition. Here, the mentioned angular parameter is selected to be the flight path angles of the munition. Making this modification, it is intended to keep the angular displacement of the line of sight at a constant value. The performance characteristics of the proposed PNG scheme are submitted over a short-range air-to-surface missile against a maneuvering ground target apart from the velocity pursuit guidance (VPG), $\mathrm{LHG}$, and BPG laws in a comparative manner. In the computer e-ISSN: 2148-2683 simulations which cover the acceleration-based PNG law and angle autopilot with a varying bandwidth, the final miss distance, engagement time, and maximum lateral acceleration requirement of the missile are chosen as the comparison criteria in addition to the total energy expenditure of the control actuation system (CAS) which constitutes one of the subsystems of the missile.

\section{Dynamic Modeling of the Missile}

The control of the air-to-surface missile whose schematic representation is shown in Figure 1 is carried out by means of the canard fins which are placed close to the nose part. In Figure $1, \vec{u}_{j}^{(b)}, \delta_{i}$, and $C_{M}$ denote the jth unit vector of the missile-fixed reference frame $\left(F_{b}\right)$ as $\mathrm{j}=1,2$, and 3 , angular displacement of ith control fin as $\mathrm{i}=1,2,3$, and 4 , and mass center of the missile, respectively.

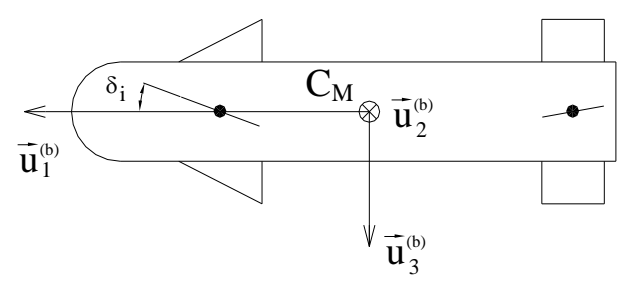

Figure 1. Missile Geometry

The dynamic behavior of the missile can be defined using the following equations [5]:

$\dot{u}-r v+q w=\left(X+X_{T}\right) / m+g_{x}$

$\dot{v}+r u-p w=\left(Y+Y_{T}\right) / m+g_{y}$

$\dot{w}-q u+p v=\left(Z+Z_{T}\right) / m+g_{z}$

$\dot{p}=L / I_{a}$

$\dot{q}-p r=\left(M+M_{T}\right) / I_{t}$

$\dot{r}+p q=\left(N+N_{T}\right) / I_{t}$

For the longitudinal, lateral, and vertical components of the relevant vectors in $F_{b}$, the forthcoming definitions are introduced:

$m$ : Mass of the missile

$I_{a}$ and $I_{t}$ : Longitudinal and lateral moment of inertia components of the missile

$p, q$, and $r$ : Components of the angular velocity vector in the roll, pitch, and yaw directions

$u, v$, and $w$ : Components of the linear velocity vector of the missile

$X, Y$, and $Z$ : Components of the aerodynamic force acting on the mass center of the missile

$L, M$, and $N$ : Components of the aerodynamic moment vector acting on the missile body vector in the roll, pitch, and yaw directions

$X_{T}, Y_{T}$, and $Z_{T}$ : Components of the thrust vector acting on the mass center of the missile

$L_{T}, M_{T}$, and $N_{T}$ : Components of the thrust misalignment moment vector acting on the missile body 
$g_{x}, g_{y}$, and $g_{z}$ : Components of the gravity vector acting on the mass center of the missile

Assuming that the angular motion of the missile in the roll plane is nullified by means of the roll autopilot prior to its motion in the pitch and yaw planes, i.e. $p \approx 0$, the equations of motion of the missile can be obtained for the phases after the burnout by regarding equations (2), (3), (5), and (6) in the following manner [5]:

$\dot{w}-q u=(Z / m)+g_{z}$

$\dot{q}=M / I_{t}$

$\dot{v}+r u=(Y / m)+g_{y}$

$\dot{r}=N / I_{t}$

The aerodynamic force ad moment components within equations (7) through (10), i.e. $X, Y, M$, and $N$, can be approximated by means of the next linear functions [5]:

$Y=C_{y} q_{\infty} S_{M}$

$Z=C_{Z} q_{\infty} S_{M}$

$M=C_{m} q_{\infty} S_{M} d_{M}$

$N=C_{n} q_{\infty} S_{M} d_{M}$

In the relationships above, $q_{\infty}, S_{M}$, and $d_{M}$ represent the dynamic pressure acting on the missile, cross-sectional area of the missile, and missile diameter, respectively. Here, the aerodynamic coefficients expressed by $C_{y}, C_{z}, C_{m}$, and $C_{n}$ can be written as functions of the angle of attack $(\alpha)$, side slip angle $(\beta)$, elevator angle $\left(\delta_{e}\right)$, rudder angle $\left(\delta_{r}\right), q$, and $r$ as follows [5]:

$C_{y}=C_{y_{\beta}} \beta+C_{y_{\delta}} \delta_{r}+C_{y_{r}}\left[d_{M} /\left(2 v_{M}\right)\right] r$

$C_{z}=C_{z_{\alpha}} \alpha+C_{z_{\delta}} \delta_{e}+C_{z_{q}}\left[d_{M} /\left(2 v_{M}\right)\right] q$

$C_{m}=C_{m_{\alpha}} \alpha+C_{m_{\delta}} \delta_{e}+C_{m_{q}}\left[d_{M} /\left(2 v_{M}\right)\right] q$

$C_{n}=C_{n_{\beta}} \beta+C_{n_{\delta}} \delta_{r}+C_{n_{r}}\left[d_{M} /\left(2 v_{M}\right)\right] r$

In these equations, $v_{M}$ indicates the magnitude of the linear velocity vector of the missile. During the computer simulations, the stability derivatives which are symbolized by $C_{y_{\beta}}, C_{y_{\delta}}, C_{y_{r}}, C_{z_{\alpha}}, C_{z_{\delta}}, C_{z_{q}}, C_{m_{\alpha}}, C_{m_{\delta}}, C_{m_{q}}, C_{n_{\beta}}, C_{n_{\delta}}$, and $C_{n_{r}}$ as functions of Mach number $\left(M_{\infty}\right)$ are updated depending on the current values of the flight parameters using the aerodynamic data tables prepared.

\section{Guidance Laws}

The PNG law is described in the pitch and yaw planes of $F_{b}$ in the following manner [5]:

$a_{p}^{c}=-N_{p} v_{M} \dot{\lambda}_{p} \cos \left(\lambda_{y}-\eta_{m}\right)$

$a_{y}^{c}=N_{y} v_{M}\left[\dot{\lambda}_{y} \cos \left(\gamma_{m}\right)-\dot{\lambda}_{p} \sin \left(\gamma_{m}\right) \sin \left(\lambda_{y}-\eta_{m}\right)\right](20$

where $\gamma_{m}$ and $\eta_{m}$ denote the flight path angles which are the angles of the missile velocity vector with respect to the pitch and yaw planes, respectively. As $p$ and $y$ letters indicates the pitch and yaw planes in sequel, $a_{p}^{c}$ and $a_{y}^{c}$ correspond to the reference signals to the missile control system, i.e. missile autopilot, $N_{p}$ and $N_{y}$ denote the effective navigation ratios, and $\lambda_{p}$ and $\lambda_{y}$ represent the orientation angles of the line-of-sight (LOS) vector with respect to the pitch and yaw planes of $F_{0}$.

Dividing the acceleration terms given in equations (19) and (20) by $v_{M}$ yields the guidance commands in terms of the time change of the flight path angles, i.e. $\dot{\gamma}_{m}^{c}$ and $\dot{\eta}_{m}^{c}$ :
$\dot{\gamma}_{m}^{c}=\dot{\gamma}_{m}^{c}(t)=-N_{p} \dot{\lambda}_{p} \cos \left(\lambda_{y}-\eta_{m}\right)$
$\dot{\eta}_{m}^{c}=\dot{\eta}_{m}^{c}(t)=N_{y}\left[\dot{\lambda}_{y} \cos \left(\gamma_{m}\right)-\dot{\lambda}_{p} \sin \left(\gamma_{m}\right) \sin \left(\lambda_{y}-\eta_{m}\right)\right]$

The integral of equations (21) and (22) over time gives the commands of the PNG law in terms of the flight path angles:

$\gamma_{m}^{c}=\int_{t_{1}}^{t_{2}} \dot{\gamma}_{m}^{c} d t$
$\eta_{m}^{c}=\int_{t_{1}}^{t_{2}} \dot{\eta}_{m}^{c} d t$

where, as $t$ corresponds the time variable, $t_{1}$ and $t_{2}$ stand for the initiation and termination time parameters of the discrete time segment through which the integration action is utilized.

Making $N_{p}$ and $N_{y}$ unity in equations (21) and (22), the PNG law turns into the VPG law. The aim with this law is to coincide the missile velocity vector with the virtual LOS vector between the missile and target and thus to maintain the direction of the missile velocity vector towards the target throughout the engagement [5].

The output angles of the BPG law in which the longitudinal axis of $F_{b}$ is tried to be put upon the LOS vector, i.e. $\theta_{c}$ and $\psi_{c}$, can be expressed as follows [5]:

$\theta^{c}=\lambda_{p}$

$\psi^{c}=\lambda_{y}$

In the LHG law, the position of the missile is intended to be kept on the collision triangle formed by the missile, target, and predicted collision point during the engagement duration. As per the LHG law, the guidance commands are introduced in terms of the flight path angles of the missile in the pitch and yaw planes [3], [4], [5]:

$$
\gamma_{m}^{c}=\arctan \left[\left(\Delta z-v_{T z} \Delta t\right) /\left(\varsigma_{x} \cos \left(\eta_{m}\right)+\varsigma_{y} \sin \left(\eta_{m}\right)\right)\right]
$$

$\eta_{m}^{c}=\arctan \left[\left(v_{T y} \Delta t-\Delta y\right) /\left(v_{T x} \Delta t-\Delta x\right)\right]$

where $\Delta x, \Delta y$, and $\Delta z$ stand for the components of the relative position vector between the missile and target in $F_{0}$. Also, $\Delta t$ denotes the instantaneous duration which is required for the missile to attain the prescribed collision point. In the equations, $\varsigma_{x}=v_{T x} \Delta t-\Delta x$ and $\varsigma_{y}=v_{T y} \Delta t-\Delta y$ as well. Here, $v_{T x}, v_{T y}$, and $v_{T z}$ express the components of the missile velocity vector in $F_{0}$.

\section{Missile Control System}

The autopilots are designed separately in the roll, pitch, and yaw planes of the missile in order to realize the guidance commands generated by the considered guidance law. An autopilot basically consists of a controller, CAS, gyros, accelerometers, and plant. In this arrangement, the missile constitutes the plant. In the modeling, the gyros, accelerometers, and CAS are so selected that their operating frequencies are higher than the bandwidth of the autopilots in order for them not to affect the entire missile dynamics.

The angle autopilots which realize the command signals produced by the PNG, VPG, BPG, and LHG laws by converting them into physical motion in the pitch and yaw planes can be defined using the following transfer functions [3], [5]: 
$\frac{\gamma_{m}(s)}{\gamma_{m}^{c}(s)}=\frac{n_{\gamma 3} s^{3}+n_{\gamma 2} s^{2}+n_{\gamma 1} s+1}{d_{\gamma 4} s^{4}+d_{\gamma 3} s^{3}+d_{\gamma 2} s^{2}+d_{\gamma 1} s+1}$

$\frac{\eta_{m}(s)}{\eta_{m}^{c}(s)}=\frac{n_{\eta 3} s^{3}+n_{\eta 2} s^{2}+n_{\eta 1} s+1}{d_{\eta 4} s^{4}+d_{\eta 3} s^{3}+d_{\eta 2} s^{2}+d_{\eta 1} s+1}$

where $n_{\gamma 1}, n_{\gamma 2}, n_{\gamma 3}, d_{\gamma 1}, d_{\gamma 2}, d_{\gamma 3}, d_{\gamma 4}, n_{\eta 1}, n_{\eta 2}, n_{\eta 3}, d_{\eta 1}, d_{\eta 2}, d_{\eta 3}$, and $d_{\eta 4}$ coefficients are functions of the diameter, mass, moment of inertia, and velocity components of the missile as well as the autopilot gains, dynamic pressure, and aerodynamic coefficients.

The autopilot gains are determined by equating the characteristic polynomial, i.e. the denominator polynomial, of the transfer functions given in equations (29) and (30) to a standard fourth-order Butterworth polynomial such that they provide the autopilot with having stability and desired bandwidth value [3], [5].

While the designed angle autopilots can directly be used with the PNG, VPG, and LHG laws, the forthcoming modification should be made for the case with the BPG law:

$\gamma_{m}^{c}=\theta^{c}-\alpha$

$\eta_{m}^{c}=\psi^{c}+\left[\beta / \cos \left(\theta^{c}\right)\right]$

For the comparison purpose, the transfer functions of the pitch and yaw autopilots whose reference signals are in the form of linear acceleration components are derived for the traditional PNG law [3], [5]:

$\frac{a_{z}(s)}{a_{p}^{c}(s)}=\frac{\left(T_{p} s+1\right)\left(n_{p 2} s^{2}+n_{p 1} s+1\right)}{a_{p 3} s^{3}+a_{p 2} s^{2}+a_{p 1} s+1}$

$\frac{a_{y}(s)}{a_{y}^{c}(s)}=\frac{\left(T_{y} s+1\right)\left(n_{y 2} s^{2}+n_{y 1} s+1\right)}{a_{y 3} s^{3}+a_{y 2} s^{2}+a_{y 1} s+1}$

where $T_{p}, n_{p 1}, n_{p 2}, a_{p 1}, a_{p 2}, a_{p 3}, T_{y}, n_{y 1}, n_{y 2}, a_{y 1}, a_{y 2}$, and $a_{y 3}$ parameters are functions of the diameter, mass, moment of inertia, and velocity components of the missile as well as the autopilot gains, dynamic pressure, and aerodynamic coefficients.

Similar to the angle autopilot, the gains of the acceleration autopilots are determined by equating the characteristic polynomials of the transfer functions in equations (33) and (34) to a standard third-order Butterworth polynomial [3], [5].

In the computer simulations, a roll autopilot is run at a bandwidth value four times the bandwidth of the pitch and yaw autopilots in order to make the angular motion of the missile around the roll axis zero at the beginning of the engagement.

\section{Target Kinematics}

Once the normal and tangential components of the linear acceleration vector of the ground target in $F_{0}$, i.e. $a_{T}^{n}$ and $a_{T}^{t}$, are designated as well as the initial values of its linear speed and orientation angle, i.e. $v_{T 0}$ and $\eta_{t 0}$, the linear speed and orientation angle of the target, i.e. $v_{T}$ and $\eta_{t}$ can be expressed depending on time as below [5]:

$v_{T}(t)=v_{T 0}+\int_{t_{0}}^{t} a_{T}^{t}(\sigma) d \sigma$
$\eta_{t}(t)=\eta_{t 0}+\int_{t_{0}}^{t} \frac{a_{T}^{n}(\sigma)}{v_{T}(\sigma)} d \sigma$ where $t_{0}$ demonstrates the initial time of the missile-target engagement and symbol $\sigma$ denotes the dummy integration variable.

Applying the time integral to equations (35) and (36), the expressions giving the change of the target position in time are found by taking the initial values of the horizontal target position, i.e. $x_{T O}$ and $y_{T O}$ into consideration in the following fashion [5]:

$x_{T}(t)=x_{T 0}+\int_{t_{0}}^{t} v_{T}(\sigma) \cos \left(\eta_{t}(\sigma)\right) d \sigma$
$y_{T}(t)=y_{T 0}+\int_{t_{0}}^{t} v_{T}(\sigma) \sin \left(\eta_{t}(\sigma)\right) d \sigma$

where, for the sake of simplifying the problem, the elevation of the target from the ground is taken to be constant, i.e. $z_{T}(t)=z_{T 0}$.

\section{Missile-Target Engagement Model}

In addition to the magnitude of the LOS vector, i.e. $r_{T / M}$, the LOS angles which are the angles of the LOS vector with respect to the pitch and yaw planes, i.e. $\lambda_{p}$ and $\lambda_{y}$, can be formulated as given below [5]:

$$
\begin{aligned}
& r_{T / M}=\sqrt{\Delta x^{2}+\Delta y^{2}+\Delta z^{2}} \\
& \lambda_{p}=\arctan \left[-\Delta z \cos \left(\lambda_{y}\right) / \Delta x\right] \\
& \lambda_{y}=\arctan (\Delta y / \Delta x)
\end{aligned}
$$

Since a ground target is considered in the present study, the final miss distance at the end of the engagement, i.e. dmiss, can be calculated once the vertical component of $r_{T / M}$ becomes zero, i.e. $\Delta z=0[5]$ :

$d_{\text {miss }}=\sqrt{\Delta x^{2}\left(t_{F}\right)+\Delta y^{2}\left(t_{F}\right)}$

where $t_{F}$ represents the termination time of the engagement.

\section{Computer Simulations}

The computer simulations are conducted using the MATLAB $^{\odot}$ Simulink $^{\odot}$ software under the following conditions:

- ODE 45 differential equation solver is used.

- Initial elevation and speed values of the missile are specified as $200 \mathrm{~m}$ and 1,2 Mach, i.e. $408 \mathrm{~m} / \mathrm{s}$, respectively.

- Initial position of the target with respect to the missile is taken to be $2,000 \mathrm{~m}$ horizontally and $500 \mathrm{~m}$ laterally.

- $\quad$ Target is assumed to move at a constant speed of 90 $\mathrm{km} / \mathrm{hr}$ and $0.5 \mathrm{~g}\left(\mathrm{~g}=9.81 \mathrm{~m} / \mathrm{s}^{2}\right)$ lateral acceleration.

- Aerodynamic coefficients are computed by regarding $M_{\infty}$ between 0.3 and 2.7, and taking $\delta_{e}$ and $\delta_{r}$ between -10 and $10^{\circ}$. Also, the range between -17 and $19^{\circ}$ is regarded for $\alpha$ and $\beta$.

- $\quad$ For the cases with the PNG law, $N_{p}$ and $N_{y}$ are set to 3 .

- Lateral acceleration limit of the missile is regarded to be $\pm 30 \mathrm{~g}$.

- Missile is supposed to be on the LOS at the beginning of the engagement.

- As a subsystem of the missile whose energy expenditure is much larger than the other subsystems 
and components, the total energy expenditure of the CAS which is the summation of the individual consumption of each of the four control fins, i.e. ECAS, is approximately calculated using the next equality:

$E_{C A S}=\left(\sum_{i=1}^{4}\left|K_{H M} \cdot \delta_{i} \cdot \dot{\delta}_{i}\right|\right) \cdot t_{\text {eng }}$

where $K_{H M}$ and $t_{\text {eng }}$ symbols stand for the average hinge moment coefficient of the control fins and total engagement time, respectively.

- $K_{H M}=50 \mathrm{~N} \cdot \mathrm{m} / \mathrm{rad}$ is considered.

- Total angular excursion of each control fin is limited to $\pm 20^{\circ}$.

- Angle autopilots are run in two modes. While the bandwidth of the autopilots is kept constant at $5 \mathrm{~Hz}$ in the first mode, the quantity whose initial value is $1 \mathrm{~Hz}$ reaches $5 \mathrm{~Hz}$ at the end of the first second for the sake of diminishing the lateral acceleration requirement.

Evaluating the data acquired from the computer simulations for all the designated situations, the PNG, VPG, BPG, and LHG laws are compared according to the final miss distance, engagement time, maximum lateral acceleration requirement, and total energy expenditure of the CAS. The sample engagement geometries are given in Figure 2 through Figure 7. Also, the results for the autopilots with the constantand varying-bandwith values are shown in Table 1 and Table 2

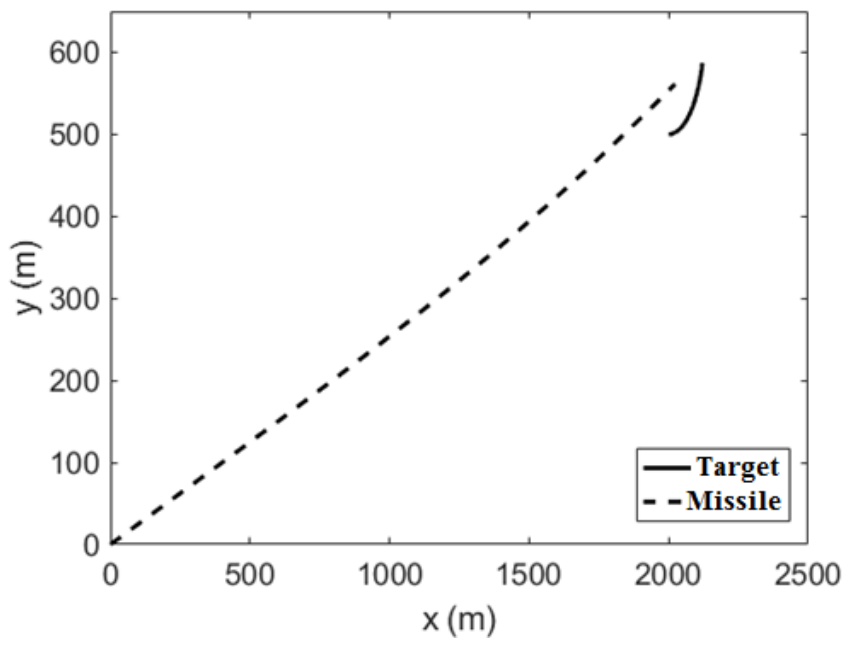

Figure 2. Horizontal Engagement Geometry for Case 1

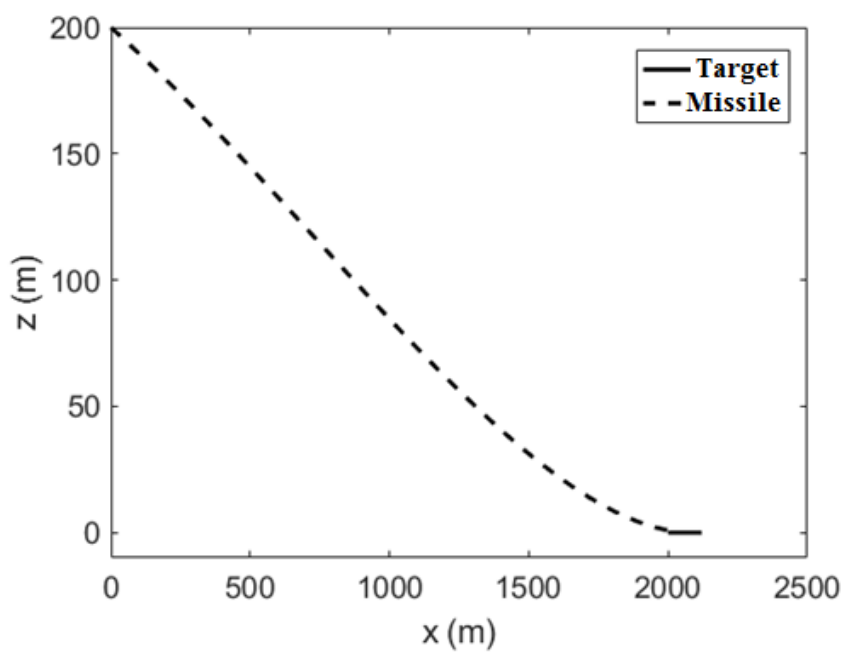

Figure 3. Vertical Engagement Geometry for Case 1

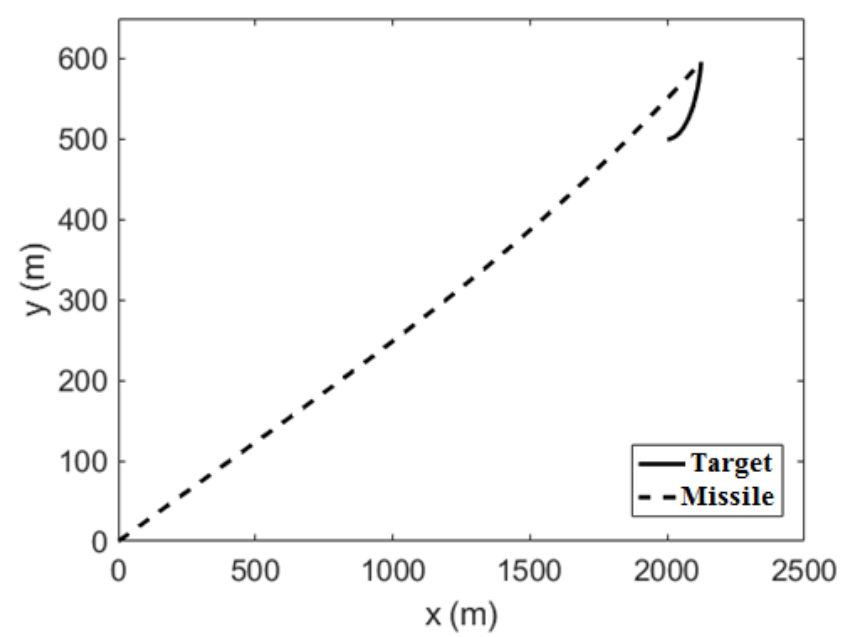

Figure 4. Horizontal Engagement Geometry for Case 2

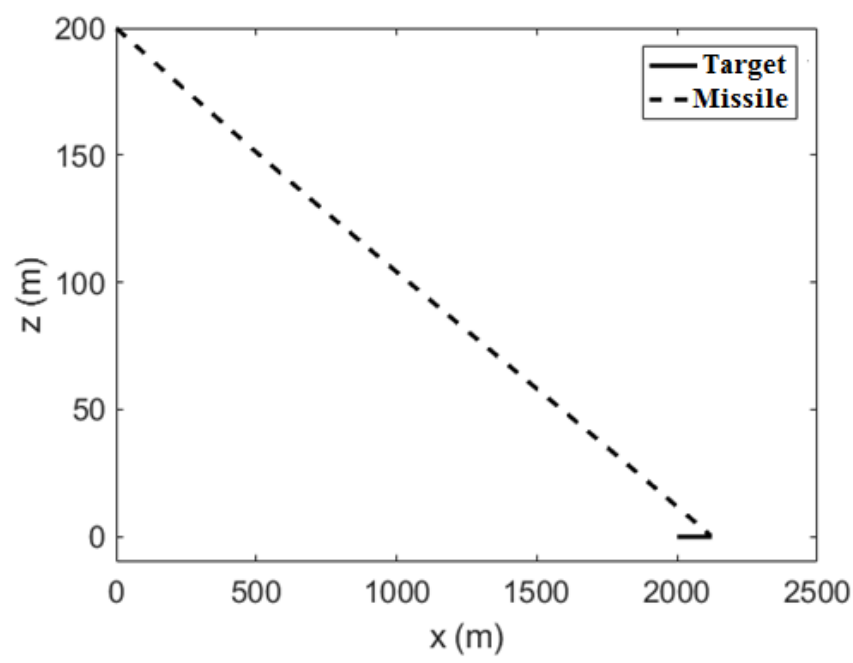

Figure 5. Vertical Engagement Geometry for Case 2 


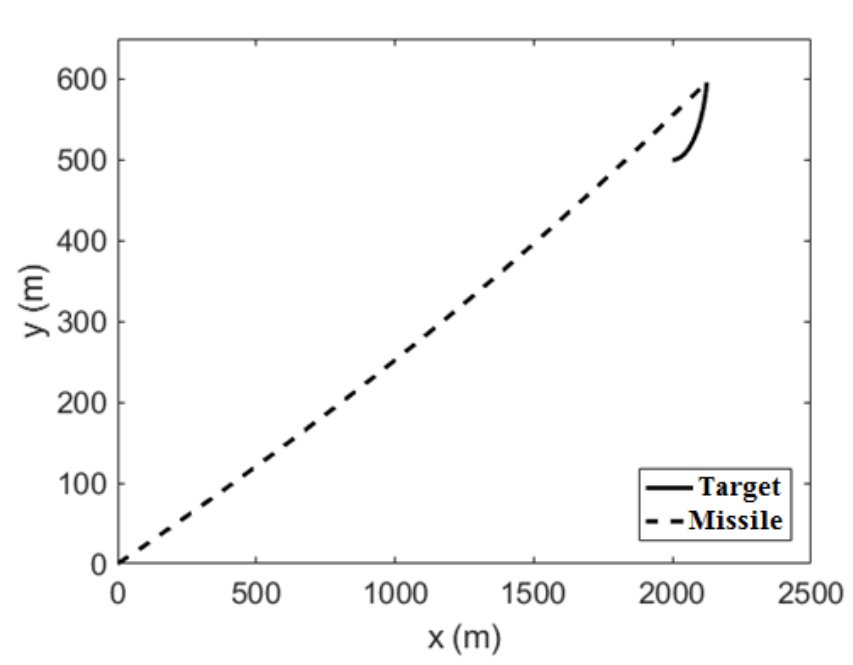

Figure 6. Horizontal Engagement Geometry for Case 5

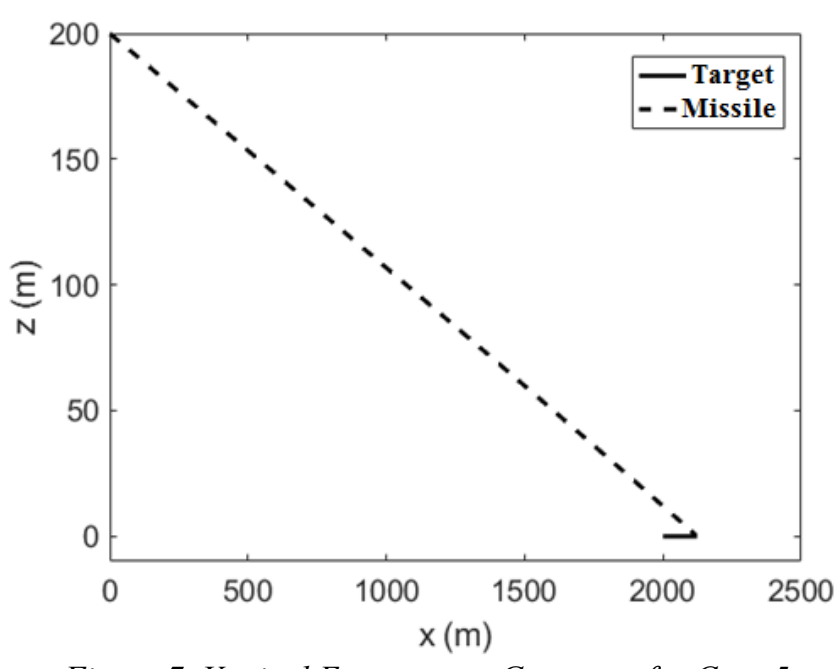

Figure 7. Vertical Engagement Geometry for Case 5

\section{Conclusions}

Evaluating the results attained at the end of the computer simulations in Table 1 and Table 2, it is observed that the anglebased PNG law with a constant-bandwidth autopilot leads to smaller miss distance than its acceleration-based counterpart. On the other hand, the engagement time, maximum lateral acceleration requirement, and total energy expenditure quantities become larger with the angle-based PNG law. Although the mentioned increment in the maximum lateral acceleration requirement seems higher than the lateral acceleration limit of the missile considered in this study, these values are, actually, within the design tolerances of the missile. When the varying-bandwidth autopilots are preferred in the simulations, smaller numbers occur for all the comparison criteria except the increasing engagement time. Hence, it can be stated that the angle-based PNG law with a varying bandwidth autopilot gets superior to the angle-based PNG law with a constant bandwidth autopilot. Besides, the angle-based PNG law produces smaller results than the cases with the LHG law for the both types of the autopilots. While reasonable data are reached with the VPG law, the final miss distance value resulted from the use of the BPG law is not acceptable to hit a target.
Consequently, it can be concluded that the angle-based PNG law yields better results than the other guidance laws considered within the present study. This law can, in fact, be utilized into autonomous mechatronic systems other than guided munition as well.

\section{References}

[1] B. Özkan, "Dynamic modeling, guidance, and control of homing missiles", PhD Thesis, Middle East Technical University, Ankara, Turkey, 2005.

[2] P. Zarchan, P., Tactical and Strategic Missile Guidance, Second Edition, Progress in Astronautics and Aeronautics, USA, 1994.

[3] B. Özkan, M. K. Özgören, and G. Mahmutyazıcıŏlu, "Performance comparison of the notable acceleration- and angle-based guidance laws for a short-range air-to-surface missile", Turkish Journal of Electrical Engineering and Computer Sciences, vol. 25, 2017.

pp. 3591-3606,

[4] B. Özkan, M. K. Özgören and G. Mahmutyazıcıŏglu, "Comparison of the notable acceleration- and angle-based guidance laws for a short-range air-to-surface missile", 18th IFAC World Congress, Milan, Italy, 2011.

[5] B. Özkan, M. K. Özgören and G. Mahmutyazıcıŏlu, "Comparison of the acceleration- and angle-based guidance laws for a short-range air-to-surface missile (in Turkish)", Automatic Control National Meeting in 2008 (TOK2008), İstanbul Technical University, İstanbul, Turkey, 2008.

[6] B. Özkan, "Guidance and control of an autonomous tracked vehicle using the linear homing guidance law (in Turkish)", Automatic Control National Meeting in 2013 (TOK2013), İnönü University, Malatya, Turkey, 2013.

[7] B. Özkan, "Guidance and control of a planar robot manipulator used in an assembly line", Transactions of the Institute of Measurement and Control, pp. 1-11, 2016.

[8] B. Özkan, "Guidance and control of a quadrotor towards a moving land platform", Gazi Journal of Engineering Sciences, vol. 3, no. 2, pp. 1-14, 2017. 
Avrupa Bilim ve Teknoloji Dergisi

Table 1. Simulation Results Obtained for the Autopilots with a Constant Bandwidth

\begin{tabular}{|c|c|c|c|c|c|c|}
\hline $\begin{array}{c}\text { Case } \\
\text { Number }\end{array}$ & $\begin{array}{c}\text { Guidance } \\
\text { Law }\end{array}$ & $\begin{array}{c}\text { Guidance } \\
\text { Command } \\
\text { Type }\end{array}$ & $\begin{array}{l}\text { Final Miss } \\
\text { Distance (m) }\end{array}$ & $\begin{array}{l}\text { Engagement } \\
\text { Time (s) }\end{array}$ & $\begin{array}{c}\text { Maximum } \\
\text { Lateral } \\
\text { Acceleration } \\
\text { Requirement } \\
\text { (g) }\end{array}$ & $\begin{array}{l}\text { Total Energy } \\
\text { Expenditure } \\
\text { (kJ) }\end{array}$ \\
\hline 1 & \multirow{2}{*}{ PNG } & $\begin{array}{c}\text { Linear } \\
\text { Acceleration }\end{array}$ & 102.068 & 6.362 & 2.585 & 20.139 \\
\hline 2 & & \multirow{4}{*}{ Angle } & 3.195 & 6.733 & 31.172 & 26.679 \\
\hline 3 & VPG & & 6.367 & 6.740 & 38.356 & 28.498 \\
\hline 4 & BPG & & 139.272 & 5.717 & 321.021 & 1080 \\
\hline 5 & LHG & & 4.339 & 6.730 & 74.041 & 38.137 \\
\hline
\end{tabular}

Table 2. Simulation Results Obtained for the Autopilots with Varying Bandwidth

\begin{tabular}{|c|c|c|c|c|c|c|}
\hline $\begin{array}{l}\text { Case } \\
\text { Number }\end{array}$ & $\begin{array}{c}\text { Guidance } \\
\text { Law }\end{array}$ & $\begin{array}{c}\text { Guidance } \\
\text { Command } \\
\text { Type }\end{array}$ & $\begin{array}{c}\text { Final Miss } \\
\text { Distance (m) }\end{array}$ & $\begin{array}{l}\text { Engagement } \\
\text { Time (s) }\end{array}$ & $\begin{array}{c}\text { Maximum } \\
\text { Lateral } \\
\text { Acceleration } \\
\text { Requirement } \\
\text { (g) } \\
\end{array}$ & $\begin{array}{c}\text { Total Energy } \\
\text { Expenditure } \\
\text { (kJ) }\end{array}$ \\
\hline 6 & PNG & \multirow{4}{*}{ Angle } & 2.381 & 6.802 & 12.636 & 23.859 \\
\hline 7 & VPG & & 6.598 & 6.802 & 34.528 & 25.829 \\
\hline 8 & BPG & & 141.298 & 5.711 & 364.401 & 1398 \\
\hline 9 & $\begin{array}{l}\text { LHG } \\
\end{array}$ & & 3.839 & 6.860 & 16.215 & 24.691 \\
\hline
\end{tabular}

